\title{
Téoros
}

Revue de recherche en tourisme

\section{Pour une augmentation des connaissances sur le tourisme}

\section{Louis Jolin}

Volume 1, numéro 1, février 1982

URI : https://id.erudit.org/iderudit/1080859ar

DOI : https://doi.org/10.7202/1080859ar

Aller au sommaire du numéro

Éditeur(s)

Université du Québec à Montréal

ISSN

0712-8657 (imprimé)

1923-2705 (numérique)

Découvrir la revue

Citer ce document

Jolin, L. (1982). Pour une augmentation des connaissances sur le tourisme.

Téoros, 1(1), 2-2. https://doi.org/10.7202/1080859ar d'utilisation que vous pouvez consulter en ligne.

https://apropos.erudit.org/fr/usagers/politique-dutilisation/ 


\section{Pour une augmentation des connaissances sur le tourisme}

Le présent cahier, consacré à une étude de l'hospitalité au Québec, est le premier d'une série de cahiers de recherche en tourisme qu'entendent réaliser le module de gestion et intervention touristiques de l'Université du Québec à Montréal et le département des études urbaines de cette même université, de qui relèvent les professeurs responsables de ce projet.

A l'instar de ce premier numéro, les cahiers de recherche, dénommés Téoros (en grec, "Celui qui voyage") publieront des rapports de recherche, des études scientifiques sur l"une ou l"autre question reliée au phénomène touristique. Quelques courtes chroniques régulières ainsi que des articles critiques sur des événements d'actualité pourront compléter le contenu de chaque cahier. Des étudiants inscrits au module de gestion et intervention touristiques ainsi que des professeurs de d'autres départements de l"UOAM, voire de d'autres maisons d'enseignement, sont associés à la production de ces cahiers de recherche qui paraîtront à tous les quatre mois.

L'absence relative de livres québécois sur le tourisme, la vocation promotionnelle des chroniques touristiques dans les médias traditionnels, la faiblesse des instruments pédagogiques actuels sur le tourisme rendent nécessaire la publication de ces cahiers de recherche qui contribueront, nous osons l'espérer, à l'augmentation des connaissances sur le phénomène touristique.

Les cahiers s'adressent, bien entendu, aux étudiants en tourisme des niveaux universitaire et collégial mais aussi à tous les travailleurs et intervenants en ce domaine.

Bénéficiant d'une subvention provenant du programme d'aide financière aux chercheurs (P.A.F.A.C.), les cahiers de recherche en tourisme doivent compter néanmoins sur la participation financière du lecteur. Chaque numéro est vendu au prix de 3,5 mais il est possible (ce que nous souhaitons ardemment/ de s'abonner aux cahiers de recherche pour le prix de 7,s par année, pour trois numéros (5, s abonnement étudiant; 10, s abonnement autres pays).

Tout commentaire sur le contenu des cahiers serait apprécié. Les articles pouvant contribuer à la recherche en tourisme seront pris en considération par le comité de lecture. Nous invitons le lecteur à écrire aux Cahiers de recherche Téoros, UQAM, C.P. 8888, Succursale A, Montréal, H3C 3 P8.

Pour les abonnements, il suffit de retourner le coupon ci-contre à l'adresse indiquée avec un chèque ou mandat à l'ordre de Cahiers de recherche Téoros.

Louis Jolin 